\title{
LIPÍDIOS ESTRUTURADOS: ALTERNATIVA PARA A PRODUÇÃO DE SUCEDÂNEOS DA GORDURA DO LEITE HUMANO
}

\author{
Roberta Claro da Silva e Luiz Antonio Gioielli* \\ Departamento de Tecnologia Bioquímico-Farmacêutica, Faculdade de Ciências Farmacêuticas, Universidade de São Paulo, Av. \\ Prof. Lineu Prestes, 580, 05508-900 São Paulo - SP, Brasil
}

Recebido em 12/2/08; aceito em 9/12/08; publicado na web em 7/5/09

\begin{abstract}
STRUCTURED LIPIDS: ALTERNATIVES FOR THE PRODUCTION OF HUMAN MILK FAT SUBSTITUTES. Human milk has characteristics of great importance for the newborn. Its composition shows all nutrients in quantity and quality needed, in addition to providing protection against infections and allergies and stimulating the immune system. Therefore, the composition of fatty acids and their distribution in the triacylglycerols are targets of studies on infant formula, and the triacylglycerols of human milk fat should serve as a model for the lipid components. This review aims to report studies of technology in lipids in order to produce structured lipids as substitutes of human milk fat.
\end{abstract}

Keywords: structured lipids; human milk fat; interesterification.

\section{INTRODUÇÃO}

Sob os pontos de vista nutricional, imunológico e de segurança, o leite humano é considerado o melhor alimento para crianças na primeira fase de sua vida. ${ }^{1} \mathrm{O}$ leite humano mantém o crescimento e desenvolvimento normais, melhora o processo gastrointestinal, favorece o vínculo mãe-filho ${ }^{2}$ e facilita os desenvolvimentos emocional, cognitivo e do sistema nervoso..$^{3-5}$

O leite materno é um líquido rico em gordura, minerais, vitaminas, enzimas e imunoglobulinas que protegem contra doenças. Apesar de o leite maduro ser formado por cerca de $87 \%$ de água, os restantes $13 \%$ são uma poderosa combinação de elementos, fundamentais para o crescimento e desenvolvimento da criança.

A secreção láctea apresenta as seguintes fases: colostro - é a secreção apresentada até 5 dias após o parto, contém o mais alto teor de proteínas, principalmente imunoglobulinas e lactoferrina. Seu conteúdo de gordura (2\%) é inferior ao do leite maduro $(3,5 \%)$; leite transicional - é a secreção entre o $6^{\circ}$ e o $15^{\circ}$ dia após o parto. A imunoglobulina diminui, enquanto a lactose, gordura e vitaminas hidrossolúveis aumentam. É a fase mais variável entre as lactantes; leite maduro - é produzido após o $15^{\circ}$ dia de lactação e, comparado ao colostro é uma secreção mais fina e aquosa. O leite inicial da mamada é mais fino e aquoso, pois, tem a função de suprir a sede e as necessidades líquidas do bebê, enquanto o leite do final da mamada tem quatro vezes mais gordura que o leite inicial, com a função de fornecer calorias ao lactente. ${ }^{6}$

As proteínas do leite humano são estrutural e qualitativamente diferentes das do leite bovino. Do conteúdo protéico do leite humano, $80 \%$ são constituídos pela lactoalbumina, enquanto que no leite de vaca a caseína corresponde a aproximadamente $80 \%$. Desse modo, a relação proteínas do soro/caseína do leite humano é aproximadamente $80 / 20$, enquanto a do leite bovino é $20 / 80$. A baixa concentração de caseína no leite humano resulta na formação de coalho gástrico mais leve, com flóculos de mais fácil digestão e com reduzido tempo de esvaziamento gástrico. ${ }^{7}$

O leite humano contém, também, diferentemente do leite de vaca, maiores concentrações de aminoácidos essenciais de alto valor biológico (cistina e taurina) que são fundamentais para o crescimento

\footnotetext{
*e-mail: lagio@usp.br
}

do sistema nervoso central. Isso é particularmente importante para o prematuro, que não consegue sintetizá-los a partir de outros aminoácidos por deficiência enzimática. ${ }^{7}$

O principal carboidrato no leite humano é a lactose, sendo que mais de 30 açúcares já foram identificados, como a galactose, frutose e outros oligossacarídeos. A concentração de lactose é de cerca de $4 \%$ no colostro e de até $7 \%$ no leite maduro. A lactose facilita a absorção de cálcio e ferro e promove a colonização intestinal com Lactobacillus bifidus.

Em relação à gordura, a principal diferença entre os leites bovino e humano está na quantidade dos ácidos graxos saturados presentes na posição sn-2 dos triacilgliceróis. No leite bovino, os ácidos palmítico e esteárico estão igualmente distribuídos entre as posições sn-1,3 (34 e $10 \%$, respectivamente) e sn-2 (32 e 10\%, respectivamente). O leite humano tem mais ácido palmítico (58\%) e menos ácido esteárico (3\%) na posição sn-2, em contraste com suas quantidades nas posições sn-1,3 (16 e $15 \%$, respectivamente) ${ }^{8}$

A composição do leite humano foi descrita e comparada ao leite bovino por Prentice, ${ }^{9}$ conforme apresentado na Tabela 1.

No Brasil existe, desde 1998, a Rede Nacional de Bancos de Leite Humano, coordenada pela FIOCRUZ ${ }^{10}$ (Fundação Instituto Oswaldo Cruz), e o Programa Nacional de Incentivo ao Aleitamento Materno, onde estão cadastradas 187 unidades de bancos de leite. Com a criação desta Rede foram desenvolvidas novas metodologias de controle de qualidade tipicamente adaptadas às necessidades nacionais, seguras e sensíveis o suficiente para serem praticadas na rotina. A qualidade dos produtos processados, estocados e distribuídos pelos Bancos de Leite deve ser fruto de esforço racional e constante em todas as etapas. A qualidade do leite humano ordenhado pode ser definida como elemento que resulta da avaliação conjunta de uma série de parâmetros, que incluem as características nutricionais, imunológicas, químicas e microbiológicas. O critério para avaliar a qualidade é complexo e incorpora os planos de amostragem, métodos de análise e padrões de qualidade. Os padrões devem ser dinâmicos e ajustados à evolução técnica do setor, resultando em produtos cada vez melhores. Além das análises microbiológicas são avaliados a acidez Dornic e o teor de gordura como controle físico-químico do produto. ${ }^{10}$

Apesar de todos os esforços em estimular o aleitamento materno, a urbanização e a falta de tempo reduziram o período de amamentação. Além disso, alguns recém-nascidos não são amamentados 
Tabela 1. Composição dos leites humano e bovino. Adaptada da ref. 9

\begin{tabular}{|c|c|c|}
\hline Composição & Leite humano & Leite bovino \\
\hline \multicolumn{3}{|l|}{ Gorduras } \\
\hline Total $(\mathrm{g} / 100 \mathrm{~mL})$ & 4,2 & 3,8 \\
\hline $\begin{array}{l}\text { Ácidos graxos de até } 8 \text { carbo- } \\
\text { nos }(\%)\end{array}$ & - & 6 \\
\hline $\begin{array}{l}\text { Ácidos graxos poliinsaturados } \\
(\%)\end{array}$ & 14 & 3 \\
\hline \multicolumn{3}{|l|}{ Proteínas (g/100 mL) } \\
\hline Total & 1,1 & 3,3 \\
\hline caseína & 0,3 & 2,5 \\
\hline$\alpha$-lactoalbumina & 0,3 & 0,1 \\
\hline lactoferrina & 0,2 & - \\
\hline $\operatorname{Ig} \mathrm{A}$ & 0,1 & 0,003 \\
\hline IgG & 0,001 & 0,06 \\
\hline lisozima & 0,05 & - \\
\hline albumina sérica & 0,05 & 0,03 \\
\hline B-lactoglobulina & - & 0,3 \\
\hline \multicolumn{3}{|l|}{ Carboidratos (g/100 mL) } \\
\hline lactose & 7,0 & 4,8 \\
\hline oligossacarídeos & 0,5 & 0,005 \\
\hline \multicolumn{3}{|l|}{ Minerais (g/100 mL) } \\
\hline cálcio & 0,030 & 0,125 \\
\hline fósforo & 0,014 & 0,093 \\
\hline sódio & 0,015 & 0,047 \\
\hline potássio & 0,055 & 0,155 \\
\hline
\end{tabular}

devido à baixa produção de leite, estado nutricional e condição de saúde desfavorável da lactante, ou até em função da morte da mãe durante ou após o parto. Conseqüentemente, existe a necessidade de fornecer meios alternativos de alimentação para aqueles recémnascidos que não podem ser amamentados. Como a demanda por alternativas ao leite humano é contínua, um sucedâneo para o leite humano deve ser tão próximo quanto possível do original, para atender às exigências nutritivas do crescimento infantil e substituir o leite materno nestes casos. Este sucedâneo deve estar o mais próximo possível das características do leite humano quantitativa e qualitativamente. ${ }^{11}$

\section{GORDURA DO LEITE HUMANO}

O leite humano contém de 3 a 5\% de lipídios, dentre os quais $98 \%$ são compostos por triacilgliceróis, ${ }^{12,13} 1,3 \%$ de fosfolipídios e $0,4 \%$ de colesterol. ${ }^{14-16}$ Os ácidos graxos representam $90 \%$ dos triacilgliceróis e $88 \%$ dos lipídios totais. ${ }^{17}$ A gordura do leite humano é a principal fonte de energia para o recém-nascido (aproximadamente 50\% das calorias totais), é fonte de ácidos graxos essenciais, como os ácidos linoléico (C18:2 n-6) e alfa-linolênico (C18:3 n-3), e participa do transporte de vitaminas (A, D, E e K) e hormônios lipossolúveis. . $^{16,18,19}$

O teor de lipídios varia de acordo com o tempo de duração da lactação ${ }^{15}$ ao longo do período do $\operatorname{dia}^{15,20,21}$ e do leite de início ou fim da amamentação. ${ }^{22}$ A concentração dos triacilgliceróis aumenta de aproximadamente $30 \mathrm{~g} / \mathrm{L}$ no colostro para $35 \mathrm{~g} / \mathrm{L}$ no leite transicional e para $40 \mathrm{~g} / \mathrm{L}$ no leite maduro..$^{23,24}$
Os ácidos graxos são em sua maioria de cadeia longa, com cerca de $50 \%$ de saturados e $50 \%$ de insaturados. O ácido palmítico consiste na maior proporção (53-70\%) dos ácidos graxos saturados. ${ }^{15,25,26}$ Mais de 200 ácidos graxos já foram identificados no leite humano, sendo que apenas 7 correspondem a cerca de $90 \%$ do total da gordura, ${ }^{27}$ representados pelos ácidos oléico, palmítico, láurico, linoléico, mirístico, esteárico e cáprico. Os ácidos graxos de cadeia média (C6 - C12) representam apenas cerca de $7 \%$.

A composição em ácidos graxos da gordura do leite humano varia de acordo com alguns fatores, como dieta, estágio de lactação, estação do ano e condições individuais da lactante. ${ }^{15,28,29}$

A gordura apresenta-se na forma de glóbulos de cerca de $4 \mu \mathrm{m}$ de diâmetro em emulsão de óleo em água, estabilizada por uma membrana contendo fosfolipídios e proteínas. ${ }^{30,31}$

Valores médios para os teores de gordura do leite humano, incluindo os ácidos graxos, estão disponíveis nos dados de nutrição do United States Departament of Agriculture. ${ }^{32}$ Agostoni et al. ${ }^{33}$ estudaram o conteúdo de gordura total e os ácidos graxos no colostro e ao longo de 12 meses de lactação, o total de ácidos graxos poliinsaturados (PUFAs), as concentrações de ácido araquidônico (AA - 20:4 n-6) e de ácido docosaexaenóico (DHA - 22:6 n-3), que permaneceram estáveis do colostro até os 12 meses de lactação.

A dieta de gorduras nos primeiros anos de vida tem sido extensivamente investigada devido às associações ao desenvolvimento cerebral. $^{34}$

Os ácidos graxos no leite humano têm distribuição posicional muito específica nas moléculas dos triacilgliceróis, e esta configuração específica tem sido sugerida como a principal causa da eficiência da absorção do leite humano. ${ }^{15,35,36}$ Embora o leite humano contenha pelo menos 170 diferentes estruturas de triacilgliceróis, apenas 30 delas representam $70 \%$ do total da gordura. A estrutura dos triacilgliceróis do leite humano que mais favorece a hidrólise pelo recém-nascido é aquela formada por ácidos graxos insaturados esterificados na posição sn-1, ácidos saturados na posição sn-2 e os de ácidos de cadeia média na posição $\mathrm{sn}-3 .{ }^{37}$

O ácido palmítico (16:0) é o ácido graxo saturado predominante, constituindo $20-25 \%$ dos ácidos graxos do leite maduro, sendo 70-75\% esterificado na posição sn-2 dos triacilgliceróis. ${ }^{25,26,38}$ Em contrapartida, o ácido palmítico presente nos óleos vegetais, largamente utilizados para a produção de fórmulas infantis, é esterificado predominantemente nas posições sn- 1 e sn- $3,{ }^{35}$ sendo que a posição sn-2 é principalmente ocupada pelos ácidos graxos insaturados..$^{35,39}$ A explicação para a esterificação preferencial do ácido palmítico na posição sn-2 nos triacilgliceróis do leite humano durante a síntese na glândula mamária ainda é incerta. Entretanto, sabe-se que a lipase pancreática hidrolisa seletivamente os ácidos graxos das posições sn-1 e sn-3, produzindo ácidos graxos livres e 2-monoacilgliceróis, sendo que o 2-palmitoilglicerol é mais bem absorvido que o ácido palmítico na sua forma livre, que tende a formar no $\mathrm{pH}$ alcalino do intestino delgado sabões insolúveis com cátions como o cálcio e o magnésio. ${ }^{35,40-46}$ Os ácidos graxos de cadeia curta e os de 18 carbonos, como o oléico e o linoléico, são bem absorvidos na forma de ácidos graxos livre. ${ }^{41,42,47,48} \mathrm{~A}$ combinação de ácidos graxos que formam os triacilgliceróis do leite humano mantém o ponto de fusão abaixo dos $38^{\circ} \mathrm{C},{ }^{7,23}$ ao passo que o ponto de fusão do ácido palmítico na forma livre é de $61-65^{\circ} \mathrm{C},{ }^{49}$ sendo muito superior ao da temperatura corporal e explicando sua baixa absorção na forma livre. ${ }^{42,47}$

Desta forma, com a presença preponderante do ácido palmítico na posição sn-2, há melhor aproveitamento pelo recém-nascido da energia proveniente dos ácidos graxos constituintes do leite materno, bem como se minimiza a perda de cálcio pelas fezes caso o ácido palmítico não fosse eficientemente absorvido, mas sim eliminado na forma de palmitato de cálcio. ${ }^{8,50-52}$ Ao contrário das crianças, os adultos apa- 
rentemente têm maior eficiência de absorção, independentemente da distribuição estereoespecífica dos ácidos graxos, mas os estudos que comprovam este ponto de vista ainda são inconsistentes. ${ }^{8}$

Fórmulas artificiais contendo o ácido palmítico esterificado na posição sn-2 também apresentaram melhor desempenho quando comparadas às que possuíam o ácido palmítico nas posições sn-1,3. ${ }^{53}$

A Tabela 2 apresenta a composição em ácidos graxos da gordura do leite humano.

Tabela 2. Distribuição dos principais ácidos graxos no leite humano. Adaptada da ref. 54

\begin{tabular}{lcccc}
$\begin{array}{l}\text { Ácidos } \\
\text { Graxos }\end{array}$ & Total & $\begin{array}{c}\text { Posição } \\
\text { sn-2(\%) }\end{array}$ & $\begin{array}{c}\text { Proporção } \\
\text { sn-2 }(\%)\end{array}$ & $\begin{array}{c}\text { Posições sn- } \\
1,3^{\mathrm{b}}(\%)\end{array}$ \\
\hline $12: 0$ & 4,9 & 5,3 & 36,0 & 4,7 \\
$14: 0$ & 6,6 & 11,2 & 57,0 & 4,3 \\
$16: 0$ & 21,8 & 44,8 & 68,0 & 10,3 \\
$18: 0$ & 8,0 & 1,2 & 5,0 & 11,4 \\
$18: 1$ n-9 & 33,9 & 9,2 & 9,0 & 46,3 \\
$18: 2$ n-6 & 13,2 & 7,1 & 18,0 & 16,3 \\
$18: 3$ n-3 & 1,2 & - & - & - \\
\hline
\end{tabular}

${ }^{\mathrm{a}}=(\mathrm{sn}-2 \mathrm{x} 100) /(3 \mathrm{x}$ total $) ;{ }^{\mathrm{b}}=(3 \mathrm{x}$ total $-\mathrm{sn}-2) / 2$

Silva et l. $^{7}$ investigaram a composição em ácidos graxos de 32 amostras de leite humano provenientes do Banco de Leite Humano do Hospital Universitário da Universidade de São Paulo. O leite de mães brasileiras apresentou composição em ácidos palmítico, oléico e linoléico muito próxima à descrita por Lien et al..${ }^{54} \mathrm{em}$ leite de mães americanas.

\section{MODIFICAÇÃO DE LIPÍDIOS}

Lipídios estruturados podem ser definidos como triacilgliceróis reestruturados ou modificados para alterar a composição em ácidos graxos e/ou sua distribuição nas moléculas de glicerol, por métodos químicos, enzimáticos ou de engenharia genética. ${ }^{52,55}$ Podem ser sintetizados com o propósito de melhorar ou modificar características físicas (polimorfismo, ponto de fusão, conteúdo de gordura sólida, viscosidade e consistência) e/ou químicas (estabilidade oxidativa) dos triacilgliceróis, bem como para modificar uma ou mais propriedades nutricionais (presença ou ausência de ácidos graxos saturados ou insaturados de fácil absorção e digestão). Também podem apresentar características favoráveis quanto à resposta imune, síntese de eicosanóides e ações antiinflamatórias. ${ }^{56} \mathrm{Com}$ o aumento do conhecimento sobre os efeitos dos ácidos graxos relacionados ao comprimento da cadeia, insaturação e distribuição estereoespecífica no metabolismo e saúde, há crescente interesse em usar óleos e gorduras para a redução do risco de doenças, bem como para a melhoria da saúde.$^{57}$ Considerar apenas a estrutura dos ácidos graxos não explica satisfatoriamente o impacto dos lipídios da dieta na composição lipídica do sangue, uma vez que a posição dos ácidos graxos nos triacilgliceróis também tem influência nos níveis de lipídios plasmáticos. ${ }^{50} \mathrm{~A}$ estereoespecificidade e o comprimento de cadeia dos ácidos graxos nas posições sn-1, sn-2 e sn-3 dos triacilgliceróis determinam o desempenho metabólico da gordura durante a digestão e absorção, sendo que há substancial conservação nos quilomicrons após a digestão dos ácidos graxos presentes na posição sn-2 dos triacilgliceróis ingeridos, bem como da estrutura estereoespecífica dos triacilgliceróis. ${ }^{8}$

Os lipídios estruturados são normalmente obtidos por interesterificação. Este processo promove mudança na distribuição dos ácidos graxos nos triacilgliceróis, afetando a natureza física e o comportamento dos lipídios. A interesterificação, catalisada por via química ou enzimática, é utilizada na indústria de óleos e gorduras para a fabricação de margarinas e shortenings e atualmente tem sido bastante empregada em virtude da preocupação com as gorduras parcialmente hidrogenadas que contêm ácidos graxos trans, que são associados com aumento do risco de doenças cardiovasculares. ${ }^{8,51,58}$

\section{INTERESTERIFICAÇÃO QUÍMICA}

A interesterificação química é uma reação ao acaso que produz completa randomização dos ácidos graxos nos triacilgliceróis. Atualmente, sob a perspectiva de custo e aplicação em larga escala, a interesterificação química parece ser o método mais atrativo. Por outro lado, a reação não tem especificidade e oferece pouco ou nenhum controle sobre a distribuição posicional dos ácidos graxos no produto final. ${ }^{59}$

A reação de interesterificação pode ser representada como:

$\mathrm{R}_{1}-\mathrm{CO}-\mathrm{OR}_{2}+\mathrm{R}_{3}-\mathrm{CO}-\mathrm{OR}_{4} \longrightarrow \mathrm{R}_{1}-\mathrm{CO}-\mathrm{OR}_{4}+\mathrm{R}_{3}-\mathrm{CO}-\mathrm{OR}_{2}$

A reação é catalisada por metais alcalinos ou alquilatos metálicos, realizada normalmente em temperaturas na faixa de $50-90{ }^{\circ} \mathrm{C} \mathrm{e}$ necessita baixos teores de umidade, acidez e peróxidos na matériaprima. Além disso, ao produzir a randomização dos triacilgliceróis, diversos produtos indesejáveis, como sabões, ésteres metílicos e mono e diacilgliceróis são formados durante a reação, exigindo refinação posterior. ${ }^{60,61}$

\section{INTERESTERIFICAÇÃO ENZIMÁTICA}

Sob a perspectiva de produzir lipídios com composições específicas para aplicações funcionais e medicinais, os métodos de interesterificação enzimática são mais interessantes. ${ }^{57,62} \mathrm{O}$ uso de lipases como biocatalisadores para a modificação da estrutura dos triacilgliceróis vem crescendo.

As lipases ocorrem na natureza e são ativas na interface óleo-água de emulsões. ${ }^{55}$ São enzimas obtidas predominantemente de bactérias, leveduras e fungos ${ }^{49,63-65}$ Importantes aplicações têm sido realizadas nas indústrias alimentícias e farmacêuticas. A maioria das reações enzimáticas é realizada em reatores por bateladas, apresentando alguns inconvenientes como altos custos operacionais, baixa produtividade, alta variação na qualidade dos produtos obtidos e problemas de remoção da enzima. ${ }^{66}$

Visando a obtenção de reações com maior uniformidade tecnológica e viabilidade econômica, a utilização de enzimas na forma imobilizada permite considerável aumento na estabilidade e maior diversidade de aplicação, de fundamental importância para o desenvolvimento de processos associados à bioconversão. ${ }^{67} \mathrm{~A}$ utilização de enzimas imobilizadas confere maior produtividade, facilidade na automação de processos e operações contínuas, controle preciso da extensão das reações, facilidade de separação dos produtos obtidos, estabilização da atividade enzimática, facilidade de recuperação e reutilização das enzimas. ${ }^{68}$

Reatores contínuos são utilizados associados a enzimas imobilizadas para produção em larga escala de lipídios estruturados. O sistema permite a produção em escala comercial, minimiza os custos e facilita o controle do processo, além de produzir poucos subprodutos e apresentar facilidade de operação. ${ }^{69}$ Em reatores contínuos, como o substrato entra em contato com grande quantidade de enzima, o tempo 
de reação é menor quando comparado com o reator descontínuo, resultando em menor migração acil.

A interesterificação enzimática tem a vantagem de permitir grande controle sob a distribuição posicional dos ácidos graxos do produto final, devido à seletividade e regioespecificidade das lipases. ${ }^{59} \mathrm{As}$ lipases hidrolisam os triacilgliceróis em monoacilgliceróis, diacilgliceróis, ácidos graxos livres e glicerol. Além da reação de interesterificação, as lipases podem também catalisar as reações de esterificação direta, de acidólise e de alcoólise, ${ }^{55}$ representadas a seguir:

Esterificação direta:

$$
\mathrm{R}_{1}-\mathrm{CO}-\mathrm{OH}+\mathrm{R}_{2}-\mathrm{OH} \longrightarrow \mathrm{R}_{1}-\mathrm{CO}-\mathrm{OR}_{2}+\mathrm{H}_{2} \mathrm{O}
$$

Acidólise:

$\mathrm{R}_{1}-\mathrm{CO}-\mathrm{OR}+\mathrm{R}_{2}-\mathrm{CO}-\mathrm{OH} \longrightarrow \mathrm{R}_{2}-\mathrm{CO}-\mathrm{OR}+\mathrm{R}_{1}-\mathrm{CO}-\mathrm{OH}$

Alcoólise:

$$
\mathrm{R}-\mathrm{CO}-\mathrm{OR}_{1}+\mathrm{R}_{2}-\mathrm{OH} \longrightarrow \mathrm{R}-\mathrm{CO}-\mathrm{OR}_{2}+\mathrm{R}_{1}-\mathrm{OH}
$$

As reações catalisadas por lipases são a combinação de hidrólise e esterificação. A atividade de água deve ser controlada, para aumentar a esterificação e minimizar a hidrólise, aumentando a taxa de conversão. Quando o excesso de água é presente, a hidrólise é predominante, resultando em acúmulo de glicerol, ácidos graxos livres, mono e diacilgliceróis. ${ }^{52}$ As temperaturas comumente usadas são ao redor de $70^{\circ} \mathrm{C} .11,62,70$

Os lipídios estruturados podem ser produzidos com a utilização de lipases em solventes orgânicos, na qual os substratos são solúveis e a hidrólise pode ser minimizada. O tipo de solvente empregado pode afetar drasticamente a cinética da reação e aumentar a eficiência da enzima. Outros fatores que afetam a atividade enzimática são o pH, a proporção molar dos substratos, o tempo de incubação e a especificidade da enzima. ${ }^{60}$

\section{LIPÍDIOS ESTRUTURADOS - SUCEDÂNEOS DOS LIPÍDIOS DO LEITE HUMANO}

As melhorias do desenvolvimento de fórmulas infantis se deram paralelas aos avanços das técnicas analíticas que permitiram determinação mais precisa de vários nutrientes e seus correspondentes níveis no leite humano. Conseqüentemente, tentativas em combinar a composição do leite humano focalizaram primeiramente na quantidade dos nutrientes. Posteriormente, ficou claro que a qualidade destes nutrientes é crítica quanto à sua biodisponibilidade. ${ }^{71}$ Como exemplo, se passou a selecionar os óleos vegetais a partir do perfil de ácidos graxos para serem usados como componente lipídico da fórmula infantil. A maior parte das fórmulas infantis é produzida por mistura de diferentes óleos vegetais ou misturas da gordura do leite bovino e óleos vegetais, que são similares quanto ao perfil de ácidos graxos do leite humano. No entanto, como são diferentes quanto à distribuição estereoespecífica, ocorrem problemas aos recém-nascidos que se alimentam de fórmulas artificiais. ${ }^{72}$

Diversas pesquisas foram feitas para avaliar a absorção de lipídios estruturados sucedâneos da gordura do leite humano. . $^{25,41,54,73}$

A gordura de leite humano pode ser sintetizada artificialmente para a produção de fórmulas infantis com manutenção de suas propriedades físicas, químicas e nutritivas. ${ }^{11,74-76}$

Kennedy ${ }^{77}$ relatou algumas vantagens dos lipídios estruturados e, dentre elas, o fato destes melhorarem a função do sistema imunológico. $\mathrm{O}$ excesso de ácido araquidônico, decorrente de dietas ricas em ácidos graxos n-6 leva a um excesso de eicosanóides, que podem suprimir funções imunológicas como a produção de anticorpos. Esta característica se mostra essencial aos recém-nascidos que se alimentam de fórmulas artificiais.

Kennedy et al..$^{48}$ relataram que a ingestão de lipídios estruturados por recém-nascidos aumentou a absorção dos ácidos graxos, de cálcio, provocou diminuição na formação de sabões de cálcio e conseqüente aumento na mineralização dos ossos.

Muitos pesquisadores comprovaram que a estrutura dos lipídios do leite humano pode ser artificialmente produzida pela interesterificação enzimática utilizando como catalisador a lipase específica sn-1,3. ${ }^{13,38,49,73,78-83}$ Pesquisadores patentearam diferentes métodos de produção de lipídios estruturados e utilização em fórmulas infantis na Europa ${ }^{84}$ e na Austrália. ${ }^{78}$

Diferentes tipos de óleos e gorduras são utilizados como substratos para a produção de lipídios estruturados sucedâneos da gordura do leite humano, como o tripalmitoilglicerol, gordura suína (banha), gordura do leite bovino, óleo de soja, óleo de canola, óleo de borage e óleo de girassol.

Dentre eles, a banha possui características favoráveis à utilização como matéria-prima para a produção de lipídios estruturados sucedâneos da gordura do leite humano, pois, diferentemente da gordura corpórea humana e de outros mamíferos, apresenta distribuição de ácidos graxos específica, com o ácido palmítico preferencialmente esterificado na posição sn-2, tipo de estrutura encontrada na gordura do leite humano. ${ }^{25,85} \mathrm{~A}$ banha é rica nos ácidos palmítico e oléico, na proporção aproximada de 1:2, que correspondem a cerca de $75 \%$ de seus ácidos graxos. Devido à predominância do ácido palmítico na posição sn-2, os principais triacilgliceróis da banha são StPO, OPL e OPO (onde $\mathrm{St}=$ esteárico, $\mathrm{P}=$ palmítico, $\mathrm{O}=$ oléico e $\mathrm{L}=$ linoléico) ${ }^{8}$ Mais da metade dos triacilgliceróis é composta por esses dois ácidos graxos. Dentro de certos limites, a composição da gordura dos suínos pode ser influenciada pela sua dieta, sendo que cerca de $30 \%$ do peso da carcaça é de gordura, podendo chegar a $50 \%$ em animais excessivamente gordos. ${ }^{89}$ Os avanços da zootecnia trouxeram acréscimos nas quantidades de ácidos graxos poliinsaturados aos tecidos adiposos de suínos. ${ }^{90}$ A carne suína é a mais consumida no mundo, segundo dados do USDA ${ }^{32}$ com projeções de crescimento para os próximos anos, o que torna a banha, subproduto da produção de carnes, uma matéria-prima de baixo custo.

Silva e Gioielli ${ }^{74}$ produziram lipídios estruturados a partir da interesterificação de banha e óleo de soja em diferentes proporções usando como catalisador o metóxido de sódio. Dentre as misturas modificadas, as que continham banha com 20 e $40 \%$ de óleo de soja foram as que mais se aproximaram da composição em ácidos graxos dos lipídios do leite humano.

A empresa Unilever comercializa um sucedâneo dos lipídios do leite humano com o nome comercial Betapol ${ }^{\mathrm{TM}}$, que foi o primeiro lipídio estruturado comercial obtido por via enzimática. ${ }^{52} \mathrm{O}$ triacilglicerol predominante no Betapol é o 1,3-dioleoil 2-palmitoilglicerol, cuja estrutura pode ser observada na Figura 1.

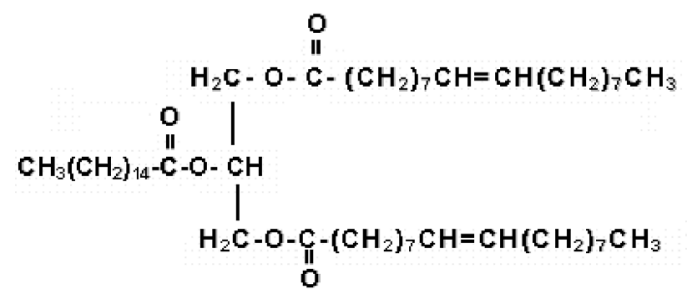

Figura 1. Estrutura do principal triacilglicerol do Betapol 
O Betapol baseia-se na modificação enzimática de tripalmitoilglicerol e óleo de girassol alto oléico ou óleo de soja, empregando lipase sn-1,3 específica. O produto formado consiste principalmente em mistura de triacilgliceróis do tipo insaturado - palmítico - insaturado (IPI, onde $\mathrm{P}=$ palmítico e $\mathrm{I}=$ insaturado, que pode ser ácido oléico ou linoléico). O esquema da reação pode ser observado na Figura 2. O produto é usado como constituinte de formulações para crianças, pois simula a gordura do leite humano quanto às suas características. ${ }^{73}$

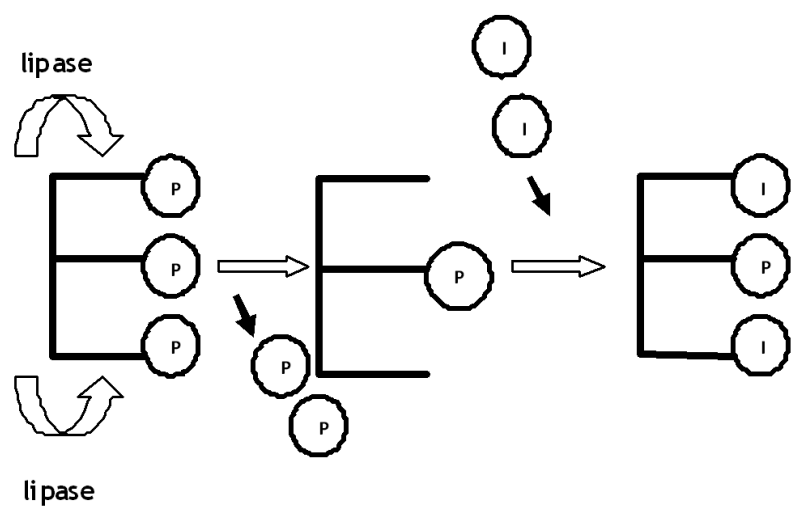

Figura 2. Esquema de produção do Betapol ( $P=$ ácido palmítico, $I=$ ácido graxo insaturado)

Silva et al. ${ }^{7}$ compararam as propriedades físicas da gordura do leite humano e do Betapol e concluíram que o Betapol apresenta menores valores para consistência, conteúdo de gordura sólida e pontos de fusão e amolecimento que a gordura do leite humano. Os comportamentos de cristalização também foram diferentes.

Christensen e Holmer ${ }^{79}$ investigaram a composição em ácidos graxos do leite humano de 5 mulheres para servir de parâmetro na produção de um sucedâneo da gordura do leite humano. Para a interesterificação foi utilizada como matéria-prima a gordura do leite bovino e como biocatalisador da reação foi utilizada a enzima sn-1,3 específica de Rhizomucor miehei. Obteve-se lipídio de diferente composição em ácidos graxos quando comparado à gordura do leite humano, mas com semelhante distribuição estereoespecífica na cadeia dos triacilgliceróis, contendo a maior parte do ácido palmítico esterificado na posição sn-2.

Mukherjee e Kiewitt ${ }^{80}$ relataram a interesterificação enzimática entre a tripalmitoilglicerol e óleo de canola. A reação foi catalisada por duas lipases, a enzima comercial Lipozyme IM e a lipase extraída do látex purificado do fruto Carica papaya. As condições da reação corresponderam a $6 \mathrm{~h}, 60{ }^{\circ} \mathrm{C}$ e $9 \%$ de cada enzima. Os resultados indicaram que ambos lipídios obtidos tiveram em sua estrutura de triacilgliceróis o ácido palmítico predominantemente esterificado na posição sn-2, enquanto os ácidos poliinsaturados provenientes do óleo de canola foram esterificados nas posições sn-1,3, características essenciais em análogos da gordura do leite humano.

Pesquisas reportam que o ácido araquidônico tem função de acelerar o crescimento de recém-nascidos. ${ }^{88,89}$ Shimada et al..$^{90}$ utilizaram a acidólise do tripalmitoilglicerol com ácido araquidônico usando a lipase sn-1,3 específica de Rhizopus delemar para sintetizar o 1,3-araquidonoil-2-palmitoilglicerol. A mistura de ácido araquidônico/tripalmitoilglicerol (5:1) foi adicionada de $0,2 \mathrm{~g}$ de água e $0,7 \mathrm{~g}$ da lipase imobilizada e incubada a $40{ }^{\circ} \mathrm{C}$ por $24 \mathrm{~h}$. O produto obtido apresentou cerca de $60 \%$ do ácido araquidônico esterificado nas posições sn-1,3 e cerca de $30 \%$ do ácido palmítico esterificado na posição sn-2, demonstrando ter características favoráveis à sua utilização como sucedâneo da gordura do leite humano.
Yang et al. ${ }^{13}$ interesterificaram a banha e os ácidos graxos do óleo de soja utilizando a enzima Lipozyme IM $^{\circledR}$ de Rhizomucor miehei. Foram utilizadas as seguintes condições de reação: temperatura de $61{ }^{\circ} \mathrm{C}, 3,5 \%$ de água, $13,7 \%$ de enzima, incubação por $1 \mathrm{~h}$ na mistura banha/ácidos graxos do óleo de soja na proporção de $1 / 2,4$. Os autores obtiveram lipídio estruturado com características semelhantes à gordura do leite humano de mães chinesas quanto à composição em ácidos graxos e distribuição estereoespecífica.

Yang et al. ${ }^{83}$ utilizaram as enzimas Lipozyme IM ${ }^{\circledR} \mathrm{TL}$ de Thermomyces lanuginosa para interesterificar o tripalmitoilglicerol com ácido caprílico e óleo de girassol, visando produzir lipídio estruturado semelhante ao lipídio do leite humano. As melhores incorporações de ácido palmítico (42\%) foram obtidas nas seguintes condições: $20 \%$ de enzima por $20 \mathrm{~h}$ de reação a $40^{\circ} \mathrm{C}$.

Yang et al. ${ }^{11}$ interesterificaram enzimaticamente tripalmitoilglicerol e ácido linoléico conjugado para a obtenção de um sucedâneo da gordura do leite humano. Foi obtida reduzida taxa de migração acil com a utilização de hexano como solvente da reação.

Estudos recentes apontam interesse em suplementar fórmulas infantis com ácidos graxos como o gama-linolênico (GLA), araquidônico (AA), eicosapentaenóico (EPA) e docosaexaenóico (DHA). ${ }^{38}$ Fórmulas infantis contendo GLA, principalmente proveniente do óleo de borage, são utilizadas para agregar benefícios à saúde e exercer efeito antagônico no metabolismo do ácido araquidônico. ${ }^{92,93} \mathrm{O}$ GLA é rapidamente elongado a ácido di-homo$\gamma$-linolênico e subsequentemente, pela ação da $\Delta 5$-dessaturase, a ácido araquidônico. Sendo assim, o GLA é a alternativa de menor custo e de mais fácil acesso para a suplementação de ácido araquidônico em fórmulas infantis..$^{50,94-96}$

Sahin et al. ${ }^{38}$ interesterificaram tripalmitoilglicerol com uma mistura de ácidos graxos de óleo de avelãs e óleo de borage rico em GLA, na expectativa de obter lipídio a ser utilizado como sucedâneo da gordura do leite humano. Foram utilizadas como biocatalisadores as lipases comerciais Lipozyme ${ }^{\circledR}$ RM IM (10\%) e Lipozyme ${ }^{\circledR}$ TL IM (6\%), e para o modelo estudado as melhores condições foram: $14,8 \mathrm{~mol} / \mathrm{mol}$ (ácido graxos/tripalmitoilglicerol) e reação durante $24 \mathrm{~h}$ a $55^{\circ} \mathrm{C}$. O efeito de incorporação do GLA e do ácido oléico foi semelhante para ambas as enzimas. Os lipídios estruturados produzidos com a Lipozyme ${ }^{\circledR}$ RM IM e a Lipozyme ${ }^{\circledR}$ TL IM continham 74,9 e 73,9\% de ácido palmítico, respectivamente, sendo que este foi esterificado principalmente na posição sn-2.

Sahin et al. ${ }^{97}$ interesterificaram tripalmitoilglicerol com mistura de ácidos graxos do óleo de avelãs e ácido esteárico, utilizando como catalisador a lipase Lipozyme RM IM (10\%). Obtiveram melhor incorporação de ácido oléico $(47,1 \%)$ a $65^{\circ} \mathrm{C}$ após 24 h de reação, com relação molar de 1:3:0,75.

Srivastava et al. ${ }^{98}$ a partir da mistura tripalmitoilglicerol e ácido oléico em diferentes proporções, estudaram a utilização de enzima não específica LIP1 do microorganismo Candida rugosa para a produção de sucedâneo da gordura do leite humano. Concluíram que a incorporação de ácido oléico ao tripalmitoilglicerol foi consideravelmente menor quando se utilizou a lipase LIP1, comparando à lipase sn-1,3 específica Lipozyme ${ }^{\circledR} \mathrm{RM}$ IM.

Nielsen et al. ${ }^{99}$ produziram lipídio estruturado em reator contínuo utilizando banha e ácidos graxos do óleo de soja para obtenção de sucedâneo da gordura do leite humano, utilizando a lipase sn-1,3 específica Lipozyme ${ }^{\circledR}$ RM IM. À mistura de ácidos graxos e banha (3:1) foram adicionados $0,1 \%$ de água, e a reação se processou a $65^{\circ} \mathrm{C}$ por $1,5 \mathrm{~h}$. Os autores obtiveram lipídio estruturado com características semelhantes à gordura do leite humano, mas com baixa estabilidade oxidativa quando comparado a produtos comerciais. 
Maduko et al. ${ }^{11}$ interesterificaram tripalmitoilglicerol com mistura dos óleos de coco, açafroa e soja $(2,5: 1,1: 0,8)$ na tentativa de obter composição de ácidos graxos semelhantes à da gordura do leite humano. A reação utilizou $10 \%$ do catalisador Lipozyme ${ }^{\circledR}$ RM IM. A melhor incorporação do ácido palmítico (40-55\%) à posição sn-2 foi obtida com $3 \mathrm{~mol} / \mathrm{mol}$ de relação molar (mistura de óleos/tripalmitoilglicerol) na temperatura de $55^{\circ} \mathrm{C}$ e 14,4 h de reação.

Maduko et $a l .{ }^{76}$ produziram fórmula artificial de leite contendo lipídio estruturado e leite caprino pasteurizado. Concluíram que o leite análogo obtido apresentou composição semelhante ao leite humano quanto à composição em ácidos graxos e distribuição nas cadeias dos triacilgliceróis. Melhores resultados foram obtidos quando a fórmula continha proporção de 1:10 de tripalmitoilglicerol:mistura de óleos de coco, açafroa e soja $(2,5: 1,1: 0,8)$.

O efeito de lipídios estruturados nos níveis de colesterol e lipoproteínas do sangue parece ser mínimo quando comparado às gorduras de origem com composições em ácidos graxos similares, mas com diferentes estruturas de triacilgliceróis. Isto indica que a utilização de lipídios estruturados na dieta não leva a efeitos deletérios nos acima citados parâmetros do sangue. ${ }^{51}$ Algumas recentes pesquisas no tema podem ser observadas na Tabela 3 .

\section{ASPECTO FUNCIONAL DOS LIPÍDIOS ESTRUTURADOS SUCEDÂNEOS DA GORDURA DO LEITE HUMANO}

A funcionalidade dos ácidos graxos na nutrição de recémnascidos tem sido ferramenta importante para aprimorar a tecnologia de lipídios estruturados e alcançar a semelhança com a gordura do leite humano. A estrutura dos triacilgliceróis tem sido reportada como uma das principais razões da melhor absorção da gordura do leite humano.

Lien et al. ${ }^{54}$ demonstraram que a randomização do óleo de palma, que tem os ácidos graxos saturados preferencialmente esterificados nas posições sn-1,3, e que após a interesterificação passaram a estar esterificados também na posição sn-2, resultou em diminuição significativa nas perdas fecais de gordura.

$\mathrm{Mu}^{106}$ publicou artigo sobre a absorção dos lipídios estruturados e sua aplicação na dieta. O autor enfatiza a importância do ácido palmítico estar esterificado na posição sn-2 em sucedâneos da gordura do leite humano, o que possibilita melhor absorção e menores perdas de cálcio. Nesta revisão é descrita a maior eficiência de absorção do lipídio estruturado Betapol quando comparado aos lipídios naturais que possuem a mesma quantidade de ácido palmítico, porém esterificados principalmente nas posições sn-1,3. ${ }^{107}$

Tabela 3. Avanços na tecnologia de lipídios estruturados sucedâneos da gordura do leite humano obtidos por interesterificação enzimática

\begin{tabular}{|c|c|c|c|}
\hline Ref. & Fonte lipídica & $\begin{array}{l}\text { Condições ótimas de reação } \\
\text { (temperatura, tempo) }\end{array}$ & Microorganismo proveniente (nome comercial da lipase) \\
\hline
\end{tabular}

75

76

101
Banha: óleo de soja

Tripalmitina e mistura de óleos de coco, açafroa e soja

Tripalmitina e mistura de óleos de coco, açafroa e soja

Óleo de atum e ácido caprílico

$30{ }^{\circ} \mathrm{C}, 73 \mathrm{~h}$

EPA (20:5n-3), DPA (22:5n3), DHA (22:6n-3) e óleo de canola

$43,7^{\circ} \mathrm{C}, 44,7 \mathrm{~h}$

$24-60{ }^{\circ} \mathrm{C}$

DHA (22:6n-3) e ácido palmítico

Tripalmitina e mistura de óleos de coco, açafroa e soja

Óleo de palma, oleína de palma, azeite de oliva e óleo de girassol, óleo de peixe

Tripalmitina e ácido oléico

$65^{\circ} \mathrm{C}, 24 \mathrm{~h}$

Tripalmitina, óleo de avelã e ômega-3

$55^{\circ} \mathrm{C}, 24 \mathrm{~h}$

$65^{\circ} \mathrm{C}, 1,5 \mathrm{~h}$

$55^{\circ} \mathrm{C}, 24 \mathrm{~h}$

Tripalmitina, ácidos graxos do óleo de avelã e ácido gama-linolênico

Tripalmitina, óleo de avelã e ômega-3

$55^{\circ} \mathrm{C}, 24 \mathrm{~h}$
Candida cylindracea (AY30 $\left.{ }^{\mathrm{TM}}\right)$ e Mucor circinelloides $\left(M 10^{\mathrm{TM}}\right)$

Rhizomucor miehei (Lipozyme ${ }^{\circledR}$ RM IM)

Rhizomucor miehei (Lipozyme ${ }^{\circledR}$ RM IM)

Rhizopus delemar (lipase Rd,), Rhizopus oryzae (lipase D) Pseudomonas fluorescens, (lipase AK)

Mucor miehei (Lipozyme-IM), Pseudomonas sp. (PS-30), Candida cylindracea (AY-30 $\left.{ }^{\mathrm{TM}}\right)$

Candida antarctica (Novozyme 435), Rhizomucor miehei (Lipozyme ${ }^{\circledR}$ RM IM)

Rhizomucor miehei (Lipozyme ${ }^{\circledast}$ RM IM)

Thermomyces lanuginosa (Lipozyme ${ }^{\circledR}$ TL IM)

Candida rugosa (LIP1) e Rhizomucor miehei (Lipozyme ${ }^{\circledR}$ $R M I M)$

Rhizomucor miehei (Lipozyme ${ }^{\circledast}$ RM IM)

Rhizomucor miehei (Lipozyme ${ }^{\circledR}$ RM IM)

Rhizomucor miehei (Lipozyme ${ }^{\circledR}$ TL IM) e Thermomyces lanuginosa (Lipozyme ${ }^{\circledR}$ TL IM)

Rhizomucor miehei (Lipozyme ${ }^{\circledR}$ RM IM) 
Melhor eficiência de absorção do Betapol também foi observada por Carnielli et al. ${ }^{53}$ ao comparar a administração de diferentes fontes lipídicas a recém-nascidos.

$\mathrm{Mu}$ e Porsgaard ${ }^{51}$ compararam em sua revisão a absorção de lipídios naturais e estruturados. Concluíram que, além do perfil em ácidos graxos, a estrutura dos triacilgliceróis é importante ao considerar o efeito nutricional de óleos e gorduras.

Renaud et al. ${ }^{108}$ alimentaram ratos com diferentes fontes lipídicas durante 3 e 4 meses, e obtiveram o mesmo percentual de absorção para banha e banha interesterificada (93\%), quando comparado a óleo de palma (91\%) e óleo de palma interesterificado (88\%). Os menores valores obtidos com a utilização do óleo de palma devem-se ao seu baixo percentual de ácido palmítico esterificado na posição sn-2.

de Fouw et al.$^{45}$ compararam a absorção intestinal de gordura em ratos que receberam Betapol e óleo de palma, e obtiveram maiores valores de absorção para o Betapol (99,2\%), quando comparado ao óleo de palma $(97,9 \%)$. Sakono et al. ${ }^{109}$ alimentaram ratos por período de 3 semanas com misturas de tripalmitoilglicerol/óleo de girassol e trioleoilglicerol/óleo de girassol naturais e interesterificadas. O maior valor de absorção foi alcançado nos animais que receberam a mistura interesterificada de tripalmitoilglicerol/óleo de girassol $(89,6 \%)$.

O ácido docosaexaenóico (DHA, 22:6 n-3) tem importância no desenvolvimento cerebral e da retina em recém-nascidos. ${ }^{110,111}$ Cerca de $87 \%$ do DHA encontrado no leite humano está na forma de triacilgliceróis, sendo principalmente esterificado nas posições sn-2 ( 50\%) e sn-3 ( 42\%) dos triacilgliceróis. ${ }^{12}$ Quando lactentes recebem dietas contendo altos teores de DHA, esse ácido graxo tem seu aumento refletido no leite humano, ${ }^{113-115}$ e proporciona melhor desenvolvimento do sistema nervoso do recém-nascido.

Sala-Vila et al. ${ }^{116}$ publicaram revisão sobre a incorporação de DHA em lipídios estruturados para suplementar fórmulas infantis. Com base em pesquisas anteriores ${ }^{111,117-120}$ estes autores concluíram que, em ratos, o DHA na posição sn-2 não apresentou diferença significativa nos níveis de absorção quando comparado aos lipídios contendo DHA esterificado nas posições sn-1,3.

A maior parte dos estudos acima apresentados demonstra que a estrutura dos triacilgliceróis é um parâmetro importante na absorção lipídica e que ácidos graxos saturados são mais bem absorvidos quando estão localizados na posição sn-2 dos triacilgliceróis.

\section{CONCLUSÕES}

Os lipídios estruturados sucedâneos da gordura do leite humano devem apresentar em sua estrutura o ácido palmítico esterificado principalmente na posição sn-2 dos triacilgliceróis, característica fundamental para a dieta adequada do recém-nascido, garantindo melhor absorção dos nutrientes e diminuição das perdas.

Os lipídios estruturados sucedâneos da gordura do leite humano devem conter em sua composição ácidos graxos essenciais, importantes para o desenvolvimento do sistema nervoso e estimulação do sistema imunológico.

As lipases com especificidade para as posições sn-1,3 dos triacilgliceróis demonstram ser alternativa interessante no desenvolvimento de sucedâneos da gordura do leite humano.

Apesar das inúmeras pesquisas realizadas envolvendo diversos processos e matérias-primas, o objetivo de desenvolver lipídios estruturados semelhantes à gordura do leite humano ainda está distante de ser totalmente alcançado. Além disso, mais pesquisas deverão ser conduzidas para avaliar o desempenho destes lipídios em recém-nascidos.

\section{REFERÊNCIAS}

1. Megraud, F.; Boudara, G.; Bessand, K.; Bensid, S.; Dabis, F.; Soltana, R.; Touhahmi, M.; J. Epidemiol. Infect. 1990, 105, 73.

2. http://www.anvisa.gov.br/legis.resol.482_99.htm, acessada em Novembro 2004.

3. Anderson, J. W.; Johnstone, B. M.; Ramley, D. T.; Am. J. Clin. Nutr. 1999, 70, 525

4. Bezkorovainy, A.; Am. J. Clin. Nutr. 2001, 73, 399.

5. Calhoun, D. A.; Lunoe, M.; Du, Y.; Christensen, R. D.; Pediatrics 2000, 105, e7.

6. Pons, S. M.; Bargalló, A. C.; Folgoso,C. C.; Sabater, M. C. L.; Eur. J. Clin. Nutr. 2000, 54, 878.

7. Silva, R. C.; Escobedo, J. P.; QuintaL, V. S.; Ibidi, S. M.; Albuquerque, E. M.; Gioielli, L. A.; Quim. Nova 2007, 30, 1535.

8. Karupaiah, T., Sundram, K.; Nutr. Met. 2007, 4, 1.

9. Prentice A. Em Handbook of milk composition; Jensen, R. G., ed.; Academic Press: New York, 1995, p. 115-221.

10. http://www.fiocruz.br/redeblh/cgi/cgilua.exe/sys/start.htm?tpl=home\#, acessada em Novembro 2007.

11. Maduko, C. O.; Akoh, C. C.; Park, Y. W.; J. Dairy Sci. 2007, 90, 594.

12. Chang, M. K.; Abraham, G.; John, V. T.; J. Am. Oil Chem. Soc. 1990, 67, 832 .

13. Yang T. K.; Xu, X. B.; He, C.; Li, L. T.; Food Chem. 2003, 80, 473.

14. Jensen, R. G.; Lipid Res. 1996, 35, 53.

15. Jensen, R. G. Em Textbook of gastroenterology and nutrition in infancy; Lebenthal, E., ed.; Raven Press: New York, 1989, p.157-208.

16. Jensen, R. G.; Ferris, A. M.; Lammi-Keffe, C. J.; Henderson, R. A.; J. Dairy Sci. 1990, 73, 223.

17. Jensen, R. G. Em Structured and modified lipids; Gunstone, F. D., ed.; Marcel Dekker: New York, 2001, p. 455-464.

18. Jensen, R. G.; Hagerty, M. M.; Mcmahon, E.; Am. J. Clin. Nutr. 1978, $31,990$.

19. Lönnerdal, B. O.; J. Nutr. 1986, 116, 499.

20. Hall, W. G.; Science 1975, 190, 1313.

21. Harzer, G.; Haug, M.; Dieterich, I.; Gentner, P. R.; J. Clin. Nutr. 1983, 37, 612 .

22. Koletzko, B.; Thiel, I.; Abiodun, P. O.; J. Pediatr. 1992, 120, S62.

23. Jensen, R. G.; Lipids 1999, 34, 1243.

24. Smit, E. N.; Martini, I. A.; Mulder, H.; Boersma, E. R.; Muskiet, F. A. J.; Essent. Fatty Acids 2002, 66, 549.

25. Innis, S. M.; Dyer, R.; Quinlan, P.; Diersen-Shade, D.; J. Nutr. 1995, 125,73 .

26. Xu, X.; INFORM 2000, 11, 1121.

27. van Beusekom, C. M.; Nijeboer, H. J.; Vanderveere, C. N.;Luteyn, A. J.; Offringa, P. J.; Muskiet, F. A. J.; Boersma, E. R.; Early Hum. Dev. 1993, 32, 207.

28. Christie, W. W. Em Advanced dairy chemistry - 2 Lipids; Fox, P. F., ed.; Chapman \& Hall: London, 1995, p. 1-36.

29. Clark, R. M.; Hundrieser, K. E.; Lipids 1993, $28,157$.

30. Christie, W. W.; Clapperton, J. L.; J. Sci. Dairy Tech. 1982, 35, 22.

31. Michalski, M. C.; Briard, V.; Michel, F.; Tasson, F.; Poulain, P.; J. Dairy Sci. 2005, 88, 1927.

32. http://www.nal.usda.gov/fnic/foodcomp, acessada em Setembro 2003.

33. Agostoni, C.; Giovannini, M.; Nutr. Health 2001, 15, 183.

34. Agostoni, C.; Acta Paediatric 2003, 92, 785.

35. Lien, E. L.; J. Pediatric 1994, 125, S62.

36. Carlson, S. E.; Rhodes, P. G.; Ferguson, M. G.; Am. J. Clin. Nutr. 1986, 44, 798 .

37. Winter, C. H.; Hoving, E. B.; Muskiet, F. A. J.; J. Chrom.-Biom Appl. 1993, 616, 9 .

38. Sahin, N.; Akoh, C. C.; Karaali, A.; J. Am. Oil Chem. Soc. 2005, 82, 549. 
39. Small, D. M.; Annu. Rev. Nutr. 1991, 11, 413.

40. Chappel, J. E.; Clandinin, M. T.; Kearny-Volpe, C.; Reichman, B.; Swyer, P. W.; J Pediatrics 1986, 108, 439.

41. de Fouw, N. J.; Kivits, G. A. A.; Quinlan, P. T.; van Nielen, W. G. L.; Lipids 1994, 29, 765.

42. Jensen, R. G.; Handbook of milk composition, Academic Press: San Diego, 1995.

43. Mattson, F. H.; Volpenheim, R. A.; J. Biol .Chem. 1964, 239, 2772.

44. Tantibhedhyangkul, P.; Hashim, S. A.; Pediatrics 1979, 61, 537.

45. Carriere, F.; Barrowman, J. A.; Verger, R.; Laugier, R.; Gastroenterology 1993, 105, 876

46. Forsynth, J. S.; Nutr. Res. Rev. 1998, 11, 255.

47. Carnielli, V. P.; Luijendijk, I. H. T.; Vangoudoever, J. B.; Sukers, E. J.; Boerlage, A. A.; Degenhart, H. J.; Sauer, P. J. J. C.; J. Ped. Gastr.Nutr. 1996, 23, 553.

48. Kennedy, K.; Fewtrell, M. S.; Morley, R.; Abbott, R.; Quilan, P. T.; Wells, J. C. K.; Bindels, J. G.; Lucas, A.; Am. J. Clin. Nutr. 1999, 70, 920.

49. Gunstone, F. D.; J. Sci. Food Agric. 1999, 79, 1535.

50. Dubois, V.; Breton, S.; Linder, M.; Fanni, J.; Parmentier, M.; Eur. J. Lipid Sci. Technol. 2007, 109, 710.

51. Mu, H.; Porsgaard, T.; Progr. Lipid Res. 2005, 44, 430.

52. Osborn, H. T.; Akoh, C. C.; Compr. Rev. Food Sci. Food Safety 2002, 3 , 93.

53. Carnielli, V. P.; Luijendijk, I. H. T.; Vangoudoever, J. B.; Sukers, E. J.; Boerlage, A. A.; Degenhart, H. J.; Sauer, P. J. J.; Am. J. Clin. Nutr. 1995, 61, 1037.

54 Lien, E. L.; Boyle, F. G.; Yuhas, R.; Tomarelli, R. M.; Quinlan, P.; J. Ped. Gastr. Nutr. 1997, 25, 167.

55. Lee, K. T.; Akoh, C. C.; J. Am. Oil Chem. Soc. 1998, 75, 495.

56. Akoh, C. C.; Moussata, C. O.; J. Am. Oil Chem. Soc. 1998, 75, 697.

57. Willis, W. M.; Lencki, R. W.; Marangoni, A. G.; Crit. Rev. Food Sci. Nutr. 1998, 38, 639.

58. Gioielli, L. A. Em Entendendo a gordura: os ácidos graxos; Curi, R.; Pompéia, C.; Miyasaka, C. K.; Procopio, J., eds.; Manole: São Paulo, 2002, p. 457.

59. Willis, W. M.; Marangoni, A. G.; J. Am. Oil Chem. Soc. 1999, 76, 443.

60. Akoh, C. C. Em Food lipids chemistry, nutrition, and biotechnology; Akoh, C. C.; Min, D. B., eds.; Marcel Dekker: New York, 1998, p. 699727.

61. Ribeiro, A. P. B.; Moura, J. M. L. N.; Grimaldi, R.; Gonçalves, L. A. G.; Quim. Nova 2007, 30, 1295.

62. Criado, M.; Hernandéz-Martins, E.; Lopéz-Hernadéz, A.; Otero, C.; J. Am. Oil Chem. Soc. 2007, 84, 717.

63. Macrae, A. R.; J. Am. Oil Chem. Soc. 1983, 60, 243A.

64. Jaeger, K. E.; Ransac, S.; Dijkstra, B. W.; van Heuvel, M.; FEMS Microbiol. Rev. 1994, 15, 29.

65. Oliveira, A. L. A.; Gioielli, L. A.; Oliveira, M. N.; Ciênc. Tecnol. Aliment. 1999, 19, 270.

66. Rios, G. M.; Belleville, M. P.; Paolucci, D.; Sanchez, J.; J. Membr. Sci. 2004, 242, 189.

67. Hilal, N.; Nigmatullin, R.; Alpatova, A.; J. Membr. Sci. 2004, 238, 131.

68. Swaisgood, H. E. Em Food Enzymology; Fox, F., ed.; Elsevier: London, 1991, p. 309.

69. Xu, X.; Lipid Technol. 2002, 1, 17.

70. Haumman, B. F.; INFORM 1994, 5, 668.

71. Benson, J. D.; Masor, M. L.; Endocr. Regulat. 1994, 28, 9.

72. Straarup, E. M.; Lauritzen, L.; Faerk, J.; Hoy, C. E.; Michaelsen, K. F.; J. Pediatr. Gastr. Nutr. 2006, 42, 293.

73. Quilan, P., Moore, S.; INFORM 1993, 4, 580.

74. Silva, R. C.; Gioielli, L. A.; Rev. Bras. Ciênc. Farm. 2006, 42, 223.

75. Silva, R. C.; Cotting, L. N.; Poltronieri, T. P.; Balcão, V. M., Gioielli, L. A.; Ciênc. Tecnol. Aliment. 2009, 29, no prelo.
76. Maduko, C. O.; Akoh, C. C.; Park, Y. W.; J. Dairy Sci. 2007, 90, 2147.

77. Kennedy, J. P.; Food Technol. 1991, 45, 76.

78. Quinlan, P. T.; Chandler, I.C.; Australian Patent Au-A-10344/92, 1992.

79. Christensen, T. C.; Holmer, G.; Milchwissenschaft 1993, 48, 543.

80. Mukherjee, K. D.; Kiewit, I.; Biotechnol. Lett.1998, 20, 613.

81. Xu, X.; INFORM 2000, 11, 1121.

82. Xu, X.; Eur J. Lipid Sci. Tech. 2000, 102, 287.

83. Yang, T. K.; Fruekilde, M. B.; J. Am. Oil Chem. Soc. 2003, 80, 881.

84. Akimmoto, K.; Yamaguchi, T.; Fujikawa, S.; Europen Patent 0965578 Al, 1999.

85. Brockerhoff, H.; Hoyle, R. J.; Wolmark, N.; Bioch. Bioph. Acta (BBA) 1966, 116, 67.

86. O’Brien, R. D.; Fats and oils - Formulating and processing for applications, Technomic: Basel, 1998, p. 7-10, 33-36, 98-108.

87. Gläser, K. R.; Wenk, C.; Scheeder, R. L.; J. Sci. Food Agric. 2004, 84, 853.

88. Carlson, S. E.; Cooke, R. J.; Rhodes, P. G.; Rhodes, G. P.; Peeples, J. M. H.; Werkman, R. N. S.; J. Pediatr. 1992, 120, S159.

89. Lanting, C. I.; Fidler, V.; Huisman, M.; Touwen, B. C.; Boersma, E. R.; Lancet 1994, 12, 1319.

90. Shimada, Y.; Nagao, T.; Hamasaki, Y.; Akimoto, K.; Sugihara, A.; Fujikawa, S.; Komemushi, S.; Tominaga, Y.; J. Am. Oil Chem. Soc. 2000, 77, 89.

91. Yang, T. K.; Rebsdorf, M.; Engelrud, U.; Xu, X.; J Agric. Food Chem. 2005, 53, 1475 .

92. Kawashima, A.; Shimada, Y.; Nagao, T.; Ohara, A.; Matsuhisa, T.; Sugihara A.; Tominaga, Y.; J. Am. Oil Chem. Soc. 2002, 79, 871.

93. Watkins, S. M.; German, J. B. Em Food Lipids: Chemistry, Nutrition, and Biotechnology; Akoh, C. C.; Min, D. B., eds.; Marcel Dekker: New York, 2002, p. 559-588.

94. Redden, P. R.; Lin, X.; Horrobin, D. F. Em Structural modified food fats: synthesis, biochemistry, and use; Christophe, A. E., ed.; AOCS Press: Champaign, 1998, p. 121-128.

95. Fewtrell, M. S.; Abbott, R. A.; Kennedy, K.; Singhal, A.; Morley, R.; Caine, E.; Jamieson, C.; Cockburn, F.; Lucas, A.; J. Pediatr. 2004, 4, 471.

96. Clough, P. M. Em Structured and modified lipids; Gunstone, F. D., ed.; Marcel Dekker: New York, 2001, p. 75-117.

97. Sahin, N.; Akoh, C. C.; Karaali. A.; J. Agric. Food Chem. 2005, 53, 5779 .

98. Srivastava, N.; Sandhu, A.; Indian J. Pediatr. 2006, 73, 767.

99. Nielsen, N. S.; Yang, T.; Xu, X.; Jacobsen, C.; Food Chem. 2006, 94 , 53.

100. Maduko, C. O.; Akoh, C. C.; Park, Y. W.; J. Am. Oil Chem. Soc. 2008, 85, 197

101. Hita, E.; Robles, A.; Camacho, B.; Ramirez, A.; Esteban, L.; Jimenez, M. J.; Muñío, M. M.; González, P. A.; Molina, E. Process Biochem. 2007, 42, 415 .

102. Haman, F.; Shahidi, F.; J. Agric. Food Chem. 2006, 54, 430.

103. Fraser, B. H.; Pelmutter, P.; Wijesundera, C.; J. Am. Oil Chem. Soc. 2007, 84, 415.

104. Karabulut, I.; Turan, S.; Vural, H.; Kayahan, M.; Food Tech. Biotech. 2007, 45, 434.

105. Sahin, N.; Akoh, C. C.; Karaali, A.; J. Agric. Food Chem. 2006, 54, 3717

106. Mu, H.; Lipid Tech. 2006, 18, 271

107. Innis, S. M.; Prog. Lipid Res. 1991, 30, 103.

108. Renaud, S. C.; Ruf, J. C.; Petithory, D.; J. Nutr. 1995, 125, 229.

109. Sakono, M.; Takagi, H.; Sonoki, H.; Yoshida, H.; Iwamoto, M.; Ikeda, I. 1.; Imaizumi, K.; Nutr. Res. 1997, 17, 1131.

110. Jensen, C. L.; Am. J. Clin. Nutr. 2006, 83, S1452.

111. Lauritzen, L.; Hansen, H. S.; JøRgensen, M. H.; Michaelsen, K. F.; Prog. Lipid Res. 2001, 40, 94. 
112. Martin, J. C.; Bougnoux, P.; Antoine, J. M.; Lanson, M.; Couet, C. ; Lipids 1993, 28, 637.

113. Jensen, C. L.; Maude, M.; Anderson, R. E.; Heird, W. C.; Am. J. Clin. Nutr. 2000, 71, 292S.

114. Henderson, R. A.; Jensen, R. G.; Lammi-Keefe, C. J.; Ferris, A. M.; Dardick, K. R.; Lipids 1992, 27, 863.

115. Helland, I. B.; Saugstad, O. D.; Smith, L.; Saarem, K.; Solvoll ${ }_{\star}$ K.; Ganes $_{\perp}$ T.; Drevon, C. A.; Pediatrics 2001, 108, E82.

116. Sala-Vila, A.; Castellote, A. I.; López-Sabater, M. C.; Nutr. Res. 2008, $28,131$.
117. Valenzuela, A.; Nieto, S.; Sanhueza, J., Nuñez, M. J.; Ferrer, C.; Ann. Nutr. Metab. 2005, 49, 325.

118. Valenzuela, V.; Sanhueza, J.; Nieto, S.; Ann. Nutr. Metab. 2005, 49, 49.

119. Jensen, C. L.; Voigt, R. G.; Prager, T. C.; Zou, Y. L. L.; Fraley, J. K.; Rozelle, J. C.; Turcich, M. R.; Llorente, A. M.; Anderson, R. E.; Heird, W. C. ; Am. J. Clin. Nutr. 2005, 82, 125.

120. Sommer Hartvigsen, M.; Mu, H.; Sørig Hougaard, K.; Lund, S. P.; Xu, X.; Høy, C. E. ; Ann. Nutr. Metab. 2004, 48, 16. 